\title{
8 Addressing female genital cutting/mutilation (FGC/M) in The Gambia
}

\author{
Beyond Criminalization
}

\author{
Ebenezer Durojaye and Satang Nabaneh
}

\section{Introduction}

Female genital cutting (FGC) or sometimes referred to as female genital mutilation (FGM) or circumcision is a cultural practice in some parts of Africa that has become a subject of concern for many years. The term FGC and FGM are sometimes used interchangeably. Although human rights organizations and activists tend to prefer the use of FGM, it is often believed that this is stigmatizing and judgemental of the culture of the people. Thus, the use of FGC is believed to be non-judgemental. An estimated 200 million girls and women alive today have experienced FGC/M in 30 countries in Africa, the Middle East and Asia where this practice is concentrated. ${ }^{1}$ About 3 million girls are said to be at risk of $\mathrm{FGC} / \mathrm{M}$ annually. Indeed, it has been noted that the practice and social acceptance of $\mathrm{FGC} / \mathrm{M}$ persist in many countries. ${ }^{2}$

The WHO (2016) estimates that 100-140 million girls and women worldwide are currently living with the consequences of the FGC/M. ${ }^{3}$ It is mostly carried out on young girls at some point between infancy and the age of 15 years. In Africa, an estimated 92 million girls from ten years of age and above have undergone FGC/M. ${ }^{4}$ While recent evidence would seem to indicate that this practice is declining in some countries, however, this is not the same in other countries as the practice would seem to remain prevalent. ${ }^{5}$

According to the 2013 Demographic and Health Survey (DHS), FGM is a universal practice in The Gambia, with $75 \%$ of girls and women between 15 and 49 undergoing the practice, and $76.3 \%$ for those between 15 and $19 .{ }^{6}$ The practice is mainly performed by traditional practitioners. In 2015, the Gambian government took a giant step forward in addressing the menace of FGC/M in the country.

The purpose of this chapter is to examine the various approaches that have been adopted to address FGC/M in some African countries. In particular, the chapter discusses the pros and cons of criminalization approach to FGC/M. It then focuses on the amendment to the 2010 Women's Act in The Gambia which prohibits FGC/M. The paper evaluates the utility of the approach adopted by the Gambian government vis-a-vis its obligation under the Protocol to the African Charter on the Rights of Women (African Women's Protocol/ 
Maputo Protocol). The paper concludes by noting that while prohibition of FGC/M through sanction is important, such an approach will fail to achieve its desired aim of reducing incidence of this practice unless other complementary measures are adopted by states.

\section{$2 \mathrm{FGC} / \mathrm{M}$ in The Gambia}

FGC/M refers to 'all procedures involving partial or total removal of the external female genitalia or other injury to the female genital organs for non-medical reasons'. ${ }^{7} \mathrm{FGC} / \mathrm{M}$ is classified into four major types. These are:

- Type 1: Often referred to as clitoridectomy, this is the partial or total removal of the clitoris (a small, sensitive and erectile part of the female genitals), and in very rare cases, only the prepuce (the fold of skin surrounding the clitoris).

- Type 2: Often referred to as excision, this is the partial or total removal of the clitoris and the labia minora (the inner folds of the vulva), with or without excision of the labia majora (the outer folds of skin of the vulva).

- Type 3: Often referred to as infibulation, this is the narrowing of the vaginal opening through the creation of a covering seal. The seal is formed by cutting and repositioning the labia minora, or labia majora, sometimes through stitching, with or without removal of the clitoris (clitoridectomy).

- Type 4: This includes all other harmful procedures to the female genitalia for non-medical purposes, e.g. pricking, piercing, incising, scraping and cauterizing the genital area.

In The Gambia, FGC/M is carried out throughout childhood, with $55 \%$ of women reporting that they were circumcised before the age of five. Another $28 \%$ of women were circumcised between the ages of 5 and 9 , and $7 \%$ were circumcised between the ages of 10 and 14 . Around $85 \%$ of women circumcised indicated that what they went through involved cutting and removal of flesh. ${ }^{8}$ According to the 2018 Multiple Indicator Cluster Survey (MICs), $75.7 \%$ of women aged $15-49$ years and $50.6 \%$ for those aged $0-14$ years had undergone FGM. ${ }^{9}$ FGM is often performed by traditional practitioners commonly called circumcisers in The Gambia. The procedure is performed without anaesthesia and using knives or razor blades.

Kaplan et al., conducted a clinical study on the health consequences of FGM in The Gambia from 2008 to $2009 .{ }^{10}$ The study indicated that type 1 is most common in The Gambia accounting for the highest cases of FGC/M, followed by types 2 and 3, while type 4 is not evident. The study found that a substantial number of cases were observed with health complications arising directly from the practice of FGC/M. Complications, whether immediate or late, were present in $23.7 \%$ of the patients with type $1(137 / 577), 55.0 \%$ of patients with type $2(126 / 229)$ and $55.4 \%$ of patients with type $3(36 / 65)$. The most common immediate complication, for all types, was infection. 
Nevertheless, knowledge about the extent of health consequences of FGC/M in The Gambia remains scarce.

FGC/M is a deeply rooted and widely supported practice that is sustained through many cultural justifications that reinforce its continuation in The Gambia. Common reasons for performing FGC/M include female purity/virginity, family honour, maintenance of cleanliness and health and assurance of women's marriageability. Some also associate it with religious beliefs. ${ }^{11}$

\section{$3 \mathrm{FGC} / \mathrm{M}$ as a human rights violation}

Given the nature of FGC/M, there is a consensus that this practice tends to undermine the human rights of girls as guaranteed under international human rights law. This practice is a threat to the enjoyment of various rights of the girl-child, including the rights to life, health equality and non-discrimination, liberty, freedom from inhumane degrading treatment, dignity and autonomy. ${ }^{12}$ These rights are guaranteed in international and regional human right instruments such as the International Covenant on Economic, Social and Cultural Rights (ICESCR), International Covenant on Civil and Political Rights (ICCPR), Convention on the Elimination of all Forms of Discrimination against Women (CEDAW) and the Convention on the Rights of the Child (CRC). Different UN treaty monitoring bodies have expressed concerns about FGM and its implications for the rights of women and girls. For instance, the CEDAW Committee in General Recommendation 24 has condemned this practice as gross violation of women's rights to health, non-discrimination and life. It urges states to adopt decisive measures including imposition of sanctions on the perpetrators of this act. In its General Recommendation 30, the Committee notes that states are obligated to eliminate all forms of harmful practices that undermine the rights and dignity of women as well as perpetuate the low status of women in society. Also, the Human Rights Committee has stated that FGM is in breach of Article 7 of the ICCPR and constitutes torture or other cruel, inhuman or degrading treatment or punishment and has also raised concerns regarding its persistence.

The Committee on the Rights of the Child in its concluding observations recommended to The Gambia to adopt legal provisions fully criminalizing the practice of female genital mutilation. It also requires the state to provide physical and psychological recovery programmes for victims of FGM and establish reporting and complaints mechanisms accessible to girls who have been victims, or fear becoming victims of the practice. In addition, The Gambia should take measures to help practitioners of female genital mutilation finding alternative sources of income.

At the regional level, provisions of the African Charter on Human and Peoples' Rights (African Charter) and the Protocol to the African Charter on the Rights of Women in Africa (African Women's Protocol) are important in addressing human rights violations occasioned by FGC/M. Indeed, Article 5 of the African Women's Protocol specifically enjoins states to prohibit 'all forms of female genital mutilation, scarification and para-medicalization of female 
genital mutilation and all other practices in order to eradicate them'. The African Women's Protocol is particularly concerned that, despite the ratification of the African Charter and other international human rights instruments by the majority of African states, and their solemn commitment to eliminate all forms of discrimination and harmful practices against women, discrimination against women persists in Africa. The African Women's Protocol, therefore, aims at holistically addressing this situation. The Protocol, highlighting the implications of such practices on women's health, provides that any practice that hinders or endangers the normal growth and affects the physical and psychological development of women and girls should be condemned and eliminated. This is because such practices may hinder women from enjoying fully their fundamental rights and prevent the promotion, protection and realization of women's rights. Failure on the part of African governments to address such harmful practices will result in violation of women's inherent human rights, such as the rights to non-discrimination, equality and human dignity. As a result, the African Women's Protocol enjoins states parties to prohibit and condemn all forms of harmful practices which negatively affect the human rights of women and which are contrary to recognized international standards. ${ }^{13}$ For example, it specifically urges state parties to take all necessary measures to eliminate $\mathrm{FGC} / \mathrm{M}$ including:

... prohibition, through legislative measures backed by sanctions, of all forms of female genital mutilation, scarification, medicalisation and paramedicalisation of female genital mutilation and all other practices in order to eradicate them; ... protection of women who are at risk of being subjected to harmful practices or all other forms of violence, abuse and intolerance.

These provisions of the Women's Protocol distinctively address the elimination of FGC/M which is prevalent in many African countries. This makes the Protocol unique in the eradication of FGC/M in Africa, unlike other existing international human rights instruments such as the CEDAW ratified by many African countries. Whereas the CEDAW generally condemns cultural practices against women in order to protect their human rights, it lacks a specific provision relating to $\mathrm{FGC/M}$.

It should be noted that Article 5 of the Protocol must be read together with Article 2 which relates to elimination of all discriminatory practices against women. Moreover, the Protocol in Article 3 on violence against women enjoins African governments to ensure that victims of all violence (including those perpetuated as a result of cultural practices) are rehabilitated. This is very important in that it will ensure that the dignity and well-being of women and girls that have undertone harmful practices are safeguarded. A combined reading of these provisions would seem to show that the Protocol has adopted a three-prong approach to eradicating cultural practices such as FGC/M. 
First, the Protocol proposes the use of sanctions to curb the spread of this practice. Second, the Protocol recommends education and awareness campaign that will address behavioural change in societies. Third, the Protocol adopts a humanistic approach of rehabilitating victims of all forms of violence. This approach of the Protocol is not only pragmatic but also commendable.

It should be noted that applying criminal law to public health issues has remained very contentious and experience has shown that this may, in the long run, become ineffective. ${ }^{14}$ Indeed, such an approach may become counterproductive in the end. Therefore, the holistic approach of the Protocol will go a long way in ensuring the eradication of this practice in many African countries. This issue is explored further below. It should be noted that The Gambia has ratified virtually all these international and regional human rights instruments. The implication under international law is that the Gambian government is obligated to comply with the provisions of these internments. ${ }^{15}$

In addition, to the binding instruments, there are consensus statements and declarations relevant to this discussion. For instance, the international community during the 1995 Beijing Declaration and Platform for Action, affirmed that if women and girls were to be free from violence and coercion, cultural and patriarchal practices will need to be addressed.

The Special Rapporteur on violence against women stated that: ${ }^{16}$

those cultural practices that involve 'severe pain and suffering' for the woman or the girl child, those that do not respect the physical integrity of the female body, must receive maximum international scrutiny and agitation. It is imperative that practices such as female genital mutilation, [...] or any other form of cultural practice that brutalizes the female body receive international attention, and international leverage should be used to ensure that these practices are curtailed and eliminated as quickly as possible.

On 20 December 2012, the United Nations General Assembly adopted a historic and unanimous resolution calling on the international community to eliminate FGC/M. The then UN Secretary-General, Ban Ki Moon, commenting on the historic resolution, urged countries 'to condemn all harmful practices that affect women and girls, in particular female genital mutilation, and to take all necessary measures, including enforcing legislation, awarenessraising and allocating sufficient resources to protect women and girls from this form of violence'. ${ }^{17}$

Also in 2013, the 57th UN Commission on the Status of Women agreed on a number of resolutions including a reference to the need for states to develop policies and programmes to eliminate FGC/M as well as other forms of violence against women. ${ }^{18}$ Similarly, on 25 September 2015, the global community agreed to a new set of development goals - the Sustainable Development Goals (SDGs) - which includes a target under Goal 5 to 
eliminate all harmful practices, such as child, early and forced marriage and FGC/M, by the year 2030 .

From the foregoing, most of the human rights instruments recommend the use of sanction as a means of addressing FGC/M. This is further explored in the next section of this paper.

\section{Criminalization and $\mathrm{FGC} / \mathrm{M}$}

Over the years, different approaches have been adopted to address this serious challenge to human rights and freedom of the girl-child in the region. In their seminal article, Johansen et al., have discussed some of the approaches adopted by African countries to address FGC/M in the region. Some of these include health, criminalization and alternative/mock ceremony. These approaches have their pros and cons. In this chapter, focus will only be on use of criminalization to address FGC/M. As noted above, most of the human rights bodies and instruments seem to recommend the use of sanctions to address FGC/M.

\subsection{Criminalization}

In many African countries, the use of sanctions to address FGC/M is by far the commonest response adopted by governments. Criminalization often involves the imposition of jail sentence or fines. The essence of enacting prohibitory laws in most countries is not just to punish the culprits, but also to serve as an act of correction or maintaining moral justice in society.

One of the most popular justifications for the use of criminal sanction is the deterrence theory. The major philosophical basis for deterrence is to discourage individuals from committing a crime. The origin of this theory has been traced to the works of classical philosophers such as Thomas Hobbes, Cesare Beccaria and Jeremy Betham. In his seminal work the Levithans, Hobbes argues that human beings are inherently good or bad. ${ }^{19} \mathrm{He}$ further asserts that human beings tend to pursue their self-interests such as material gain, personal safety and social reputation, and make enemies without caring if they harm others in the process. This sometimes may be in conflict with the needs of the society they belong. Thus, the need for what he calls 'social contract' where people agree to submit to the state, which is expected to enforce the contract. According to Hobbes, even where the state strives to enforce the contract, crimes are inevitable, therefore, it is necessary that the state imposes punishment for crime higher than the benefits an individual may derive from it. This will serve to deter future commission of a crime and thus maintain the sanctity of the social contract.

In addition, Beccaria in his highly influential work, On crimes and punishments first published in 1764, has argued that human beings by nature are rationally centred and will not likely commit crimes if the costs of committing such crimes out-weight the benefits they will derive from engaging in undesirable acts. ${ }^{20}$ While he notes that the purpose of punishment should be to prevent crimes, he submits that punishments will become unjust and severe if they 
exceed what is necessary to achieve deterrence. ${ }^{21}$ In other words, punishment should serve to deter others from committing crimes and to prevent the criminal from repeating his/her crime. He holds the view that excessive imposition of punishments will aggravate rather than prevent crimes in society. Following after Becaaria, Betham in his classical work An Introduction to the Principles of Morals and Legislation, has noted that human beings are generally under the control of two sovereign masters - pain and pleasure. ${ }^{22} \mathrm{He}$ argues that morality in every society tends to promote 'the greatest happiness of the greatest number'. Consequently, he reasons that the major duty of the state is to promote the happiness of the society by punishing and rewarding. Like Beccaria, Betham cautions against arbitrary imposition of punishments but maintains that punishments should only be used to avert greater evil or control the action of the offender.

In summary, the argument of these classical philosophers is that the more serious a punishment, the more likely a rational individual will desist from commission of a crime. Thus, to prevent crimes in society, punishment must be imposed to ensure that citizens obey the law. In essence, if individuals know that they will be punished for the crimes they commit, they will likely think twice before attempting to commit a crime. This reasoning has influenced modern-day criminal justice systems in many societies. Thus, the idea that sanctions discourage commission of crimes has led to the imposition of the death penalty and other severe punishments for offenders. This thinking has influenced moves towards criminalization of FGC/M in many countries in the region. However, this reasoning has been criticized as misleading and unfounded. For instance, one of the justifications for the continued retention of the death penalty is that it serves as a deterrent for commission of serious crimes. However, a publication by the United Nations has noted that 'research has failed to provide scientific proof that executions have a greater deterrent effect than life imprisonment. Such proof is unlikely to be forthcoming. The evidence gives no positive support to the deterrent hypothesis'. ${ }^{23}$ On the contrary, countries that have abolished the death sentence tend to witness fewer serious crimes. ${ }^{24}$ The publication further identifies other disadvantages of the death penalty as being too expensive and sometimes used to target certain groups in society.

\subsection{Limitation of criminal law in addressing FGC/M}

Indeed, commentators have noted that if truly sanctions serve as deterrence to commission of crimes, the world would have been peaceful today. However, on the contrary, the world has almost been turned to a jungle where the fittest tend to survive. Despite the imposition of the death sentence and other severe punishments for offenders, the crime rates in the world have not reduced. As discussed below, similar situation plays out with regard to the criminalization of FGC/M.

Egypt is one of the African countries where the prevalent rate of FGC/M is very high. It is believed that about $91 \%$ of women are mutilated. ${ }^{25}$ It practices 
all the forms of FGC/M, subjecting women and girls to perpetual torture and health crisis. To curb this act of torture, a presidential decree was enacted in 1958. It made the practice punishable by a fine and imprisonment. Also, a resolution was signed by Egypt's Minister of Health in 1959 to medicalize the practice. This is based on the belief that carrying out this practice in a hospital under more sanitary conditions would eventually reduce some of the detrimental, physical and psychological risks associated with FGC/M. ${ }^{26}$

Similarly, in Burkina Faso the high rates of death and health effects suffered by victims of FGC/M have led to the enactment of a specific legislation prohibiting the practice. Article 380 of the Penal Code specifically punishes any person who violates or attempts to violate the physical integrity of the female genital organ. This may either be by total ablation, excision, infibulation, desensitization or by any other means. It may result in a punishment of a fine or imprisonment, depending on its gravity. Other countries such as Ghana, Senegal and Ivory Coast have laws punishing the practice. ${ }^{27}$

Most of these laws have not been effective in curbing the practice of FGC/M in affected countries. This might be due to the fact the communities where this practice is prevalent, have not been sensitized or provided with needed information on what these laws entail before enacting them. They have not been sensitized on the health hazards that the practice was causing to women and girls. It might also be that the language of these laws was not well understood, especially as the wording of these laws may seem alien. Moreover, the fact that members of the affected communities were not always carried along before these laws were enacted has made it difficult for members of the communities where it is practised to understand or respect the laws. They have considered these laws as foreign and an affront to their culture. ${ }^{28}$ Therefore, this general lack of acceptance of the laws caused the practice to persist, especially in hiding. In his seminal work, Why People Obey the Law, Tyler has noted that legitimacy and trust are crucial factors that determine whether a group of people will obey the law. ${ }^{29} \mathrm{He}$ argues further that obedience to the law is easier where the people are carried among in its conceptualization and adoption rather that when laws are imposed on the people. According to him, people obey the law not for the fear of punishment but for legitimacy sake. He reasons that law makers and those responsible for implementing the law will do much better if they ensure that the legal system is worthy of respect rather than creating fear in the people. In sum, Tyler would seem to suggest that people are more likely to obey the law if they have confidence in the system. Conversely, people will disobey the law for lack of respect no matter how severe the punishment for such disobedience. He further reasons:

To be authoritative, legal rules and decisions must affect the actions of those toward whom they are directed. A judge's ruling means little if the parties to the dispute feel they can ignore it. Similarly, passing a law prohibiting some behavior is not useful if it does not affect how often the behavior occurs. ${ }^{30}$ 
He concludes by noting that the 'regulation of behaviour through social control is inefficient and may not be effective enough to allow a complex democratic society to survive'. ${ }^{31}$ This could be true for many of the anti-FGC/FGM laws in many parts of the region.

Harmful cultural practices such as FGC/M are sensitive cultural issues falling within the spheres of women and the family in that, if women are against the practice, they may be ostracized by the family. This is due to the cultural belief that a woman's denial or rejection of the practice amounts to a cultural taboo. Thus, the total elimination of such a practice can only be effectively based on the full commitment and political will of the government. In addition to enactment of laws, they have to put programmes, structures and resources in place to intensify sensitization against the practice especially as most perpetrators do not respect the laws nor understand the human rights implications of the practice. ${ }^{32}$

\section{An analysis of The Gambian law on FGC/M vis-a-vis obligations under international law}

As noted earlier, The Gambia is a party to a number of international and regional human rights instruments that protect the rights of women in the context of cultural practices. In addition, the 1997 Constitution of The Gambia contains a catalogue of rights and freedoms under Chapter IV relevant to protecting the rights of women and girls in relation to harmful cultural practices. The rights and freedoms provided in the Constitution include the right to life and personal liberty, torture and inhuman treatment, the rights to privacy, property and fair trial, freedom of speech, conscience, assembly, association and movement, the right to political participation, and freedom from discrimination. The Constitution does not provide a specific provision against FGC/M. Given the various physical and psychological implications of FGC/M, it could arguably be considered a violation under these provisions.

It is arguable that FGC/M can be considered a violation of sections 210 and 212 of the Criminal Code of Chapter XXII (Offences Endangering life and health). Section 210 states that any person above 16 , with responsibility for a child under the age of 14 , found to have treated or exposed a child to unnecessary suffering or injury commits a misdemeanour. However, this provision is inconsistent with the definition of a child and it victimizes children. No case on FGC/M has ever been made on this provision.

The Children's Act was enacted in 2005. The Act was promulgated to ensure the effective enjoyment and enforcement of the CRC and the African Children's Charter through the incorporation of their provisions into national law. The Act clearly provides various rights that children should enjoy as well as their responsibilities, reflecting the aspirations of the African Children's Charter. Section 19 of the Children's Act 2005 states that:

no child shall be subjected to any social and cultural practices that affect the welfare, dignity, normal growth and development of the child and in 
particular, those customs and practices that are- a) prejudicial to the health of the child, b) discriminatory to the child on the grounds of sex or other status.

Section 19 of the Act does not specifically mention FGC/M as a form of harmful traditional practice. This was a compromise as the 2003 Children's Bill under Article 25 provided for the prohibition of harmful traditional practices. It stated that a person who subjects or causes a female child to be subjected to a harmful traditional practice commits an offence and liable on conviction to a fine of five thousand Dalasis. The definition of harmful traditional practice expressly includes FGC/M and its different forms. However, this was modified before the bill was passed.

The Women's Act was signed into law by the president Yahya Jammeh on 28 May 2010. It is intended to provide for the protection of women's rights in addition to the rights guaranteed under Chapter IV of the Constitution. A key deficiency of the Women's Act is the absence of an equivalent provision of Article 5 of the Protocol, dealing with 'Elimination of Harmful Traditional Practices'.

Efforts have been made to address FGC/M since the mid-1980s when the first campaign group with a specific focus on harmful traditional practices (HTPs) including FGC/M, was established. Various groups work actively to mobilize public opinion against FGC/M and also to persuade circumcizers to engage in other alternative employment. These groups have also demanded that the Gambian Government adopt a law that criminalizes FGC/M which led to a draft FGC/M Bill which was never tabled before the National Assembly. ${ }^{33}$ However, on 24 November 2015, President Jammeh declared a ban on FGC/M stating that it was a cultural and not a religious practice. He stated that for 21 years, he conducted research on the Qur'an and consulted religious leaders whether female circumcision is mentioned in the Qur'an but he did not find it there. ${ }^{34}$

\section{The Women's Amendment Act 2015}

The presidential pronouncement against FGC/M was swiftly followed by the passing of the Women's (Amendment) Bill 2015 by the National Assembly on 2 December 2015 to prohibit female circumcision. The amendment addresses one of the key deficiencies of the Women's Act 2010 which was the absence of a provision eliminating harmful traditional practices. The Amendment Act added sections 32A and 32B in the Women's Act.

The reasons for the amendment were premised on The Gambia's international and regional human rights obligations such as Article 5 of the African Women's Protocol. Thus, it was geared towards ensuring the compliance of The Gambia with its international obligation 'to prohibit female circumcision due to the proven harmful nature of the practice'. However, as will be discussed below, the drafters of the law did not wholly incorporate the provisions of the African Women's Protocol. 
Section 32A makes it an offence for any person to engage in female circumcision. and whoever contravenes it is liable on conviction to an imprisonment for a term of three years or a fine of fifty thousand Dalasis (approximately $\$ 1250$ ) or both. The Act also stipulates a life sentence in prison when the circumcision results in death.

The Act also addresses those who commission the procedure in section $32 \mathrm{~B}$ (1). It states that 'a person who requests, incites or promotes female circumcision by providing tools or by any other means commits an offence and is liable on conviction to imprisonment for a term of three years or a fine of fifty thousand Dalasis or both'. In addition, a fine of ten thousand Dalasis (approximately $\$ 250$ ) as provided in section 32B (2) of the Act is levied against anyone knowing about the practice and failing to report. In addition, although there have been concerns about the ban leading to medicalization of FGC/M, however, there has been no evidence of such happening in The Gambia. Countries such as Senegal which amended its Penal Code to prohibit FGC/M in 1999, calls for imprisonment from six months to five years, the maximum punishment which applies when FGC/M has been practised or facilitated by a member of the medical or paramedical profession..$^{35}$

Generally, people would rarely come forward to report gender-based violence cases unless there is a scandal such as the death of a child. Recently, two suspects were indicted and remanded in custody for allegedly practising FGC/M. Two people were charged with conspiracy to commit felony, prohibition of female circumcision and accomplices to female circumcision. Sunkaru Darboe (grandfather) was accused on several counts of taking, inciting and promoting female circumcision which led to the child's death. Saffiatou Darboe was charged with having knowledge about the circumcision taking place but failing to inform authorities concerned about it. The facts of the case are that on 27 February 2016 in Sakandi Village in Kiang West, the two accused persons conspired and took one Aminata Drammeh, a five-month-old baby to the circumciser for the purposes of conducting FGC/M which later resulted in her death. The accused persons denied the charges and applied for bail to which the state objected stating that another accused person was still at large, and it would not help the investigation if the accused persons were granted bail. The case was then adjourned for ruling on bail while the accused were remanded in prison. The case is still pending and no one has been convicted yet. ${ }^{36}$

There is no gainsaying that indeed the abolition of FGC/M in the Gambia is a welcoming legal and policy achievement, but the case involving the Sankandi girl was the first litmus test to determine the intentions and capacity of the state to enforce the law and fulfil its international obligations. A comprehensive and coordinated approach is crucial to accelerating the abandonment of FGC/M. A comprehensive national movement that involves all public and private stakeholders, including government institutions, community and religious leaders, educational institutions, the media, NGOs, civil society, girls and boys, and women and men can eliminate this harmful practice. 
The Gambia is known to enact laws that address specific issues such as the 2013 Domestic Violence Act and the Sexual Offences Act. It is thus surprising that an anti-FGM law was not enacted but rather was subsumed in the Women's Act 2010. However, one reason for this may be the fact that cultural practices such as FGC/M tend to evoke emotions and sentiments, thus the need to avoid singling them out for prohibition through specific laws and potential backlash. This approach is not peculiar to The Gambia, as Nigeria recently prohibits FGC/M through the enactment of the Violence against the Persons Act of 2015.

Generally, the enforcement of the Women's Act is weak. To ensure sections 32A and 32B do not become 'paper promises', it will be necessary to put in place detailed plan for implementation and monitoring as well as establishment of enforcement mechanisms such as an Anti-FGM Prosecution Unit and the Anti-FGM Board. The existence of such 'tools' may bring about accountability in terms of reporting, investigating and prosecuting FGM cases.

The challenges faced with the recent passing of legislation discouraging harmful traditional practices include lack of well-equipped local police stations with the required legislation for charging of offences and a better understanding of the law. In addition, various communities believe that some of these laws especially the laws criminalizing FGC/M and child marriage was imposed on the citizenry by the former regime and thus believe that with the new change of government, the laws no longer exist. This has therefore led to low rate of report of cases of FGC/M and child marriage.

Nevertheless, the Act constitutes a major step forward in terms of promoting and protecting the rights of women to bodily integrity and dignity. Like most other laws in other African countries prohibiting FGC/M, the Gambian Women's Act fails to incorporate the need for education and awareness programmes as an essential part of addressing this cultural practice. As noted earlier, the African Women's Protocol enjoins African governments to embark on educations and awareness programmes to supplement the efforts in combating harmful cultural practices including FGC/M. This is a missed opportunity on the part of the drafters of Women's Act. Nabaneh and Muula have argued that the use of criminal sanction to address FGC/M is not sufficient and must be complemented with other strategies including mobilization and awareness campaign programmes. ${ }^{37}$

Although female circumcision is now banned in the country, there is need for continuous intensive education of practicing communities. This would seem to be consistent with the approach adopted by the African Women's Protocol. A long-standing and cherished traditional practice may not easily go away with the enactment of a law. It could, on the contrary, drive the practice underground and make it more harmful and dangerous for the children. For instance, Egypt is among those countries where efforts are underway towards the reduction and eventual eradication of FGC/M. The country has employed strategies such as a strong media campaign, a fatwa against FGC/M by the grand mufti of Egypt and the amendment of the decrees. Nevertheless, many people 
still consider FGC/M part of their culture or religion and identity. Appiah has argued that deep-rooted cultural practices such as FGC/M would need to be made less 'honourific' before it can be totally eradicated among the people. ${ }^{38}$ He notes further that deep-rooted cultural practices cannot be easily eradicated through mere appeals to reason, morality, law or persuasion. Appiah's argument would seem to sum up the point that the mere imposition of criminal sanction on FGC/M will not necessarily lead to the eradication of the practice. This would seem to reinforce the argument by Tyler that criminal sanction alone will not deter people from disobeying the law unless there is general acceptance and legitimacy of the process leading to its enactment. ${ }^{39}$

It is therefore vital that in The Gambia, there is continuous engagement and dialogue with the practicing communities, including circumcisers, religious leaders and traditional gate keepers, popularization of the law to every nook and cranny of the country, enhancing coordination among relevant sectors and empowerment of children and young people are necessary conditions to bring about lasting change.

The CEDAW Committee in its General Recommendation 31 has emphasized the need for states to embark on awareness and education programmes with a view to eradicating harmful practices that may impair women and girls from enjoying their fundamental rights and freedoms. One of the advantages of education and awareness programmes is that it may lead to behavioural change in the communities where FGC/M is practiced. This will be consistent with the aim of the African Women's Protocol in preventing violence against women and girls.

The Human Rights Committee in 2018 recommended that The Gambia strengthen the Women's (Amendment) Act of 2015, which criminalizes FGC/M, and enhance public awareness, particularly among traditional and religious leaders, of the lifelong negative consequences of such practices. In addition, more than 15 recommendations from the recently concluded Universal Periodic Review were on FGC/M focusing on the need for government to raise awareness and enforce the legislation, as well as strengthen and accelerate mechanisms aimed at eradicating the practice..$^{40}$

Another important omission in the Women's Act is the fact that it fails to address the situation of victims of FGC/M. Unlike the African Women's Protocol, which urges states to ensure that victims of violence are rehabilitated, the Women's Act seems ominously silent on this. While it is important to go after those that perpetrate this act, it is equally important to provide for the needs of those that have undergone the practice and suffered some health consequences. This is consistent with a human rights-based approach, which is often centred on respect for human dignity. It is believed this will go a long way in further cementing the fundamental rights of women and girls who are victims of this harmful cultural practice. A substantive approach to equality requires that the historical disadvantaged position of women is taken into consideration in responding to gender inequality. Given that FGC/M is a manifestation of the patriarchal tradition of many African societies, prohibition of the 
practice alone will not suffice to assuage the injustice it portends for women. A more pragmatic and holistic approach is needed which reflects the lived experiences of women and girls that have undergone this practice.

There is no doubt that the abolition of FGC/M in the Gambia is a welcome legal and policy development. A comprehensive and coordinated approach is crucial to accelerating the abandonment of FGC/M. Such a movement must include all public and private stakeholders, including government institutions, community and religious leaders, educational institutions, the media, NGOs, civil society, girls and boys, and women and men. Examples from some countries in the region have shown that a combination of different strategies is imperative to addressing the challenge posed by FGC/M. In Egypt for instance, the Positive Deviance Approach, which include, one-on-one education talk, community awareness campaigns, involvement of local communities on discussions relating to FGC/M, collaboration between NGOs working on FGC/M and community members and training and empowerment of people to realize the negative effects of FGC/M, has recorded modest success. ${ }^{41}$ This project has elicited open discussions among community members on the cultural relevance of FGC/M and whether it should still be retained. Moreover, a considerable reduction in the number of girls circumcised was observed during the execution of the project. ${ }^{42}$

\section{Conclusion}

This chapter has discussed some of the approaches to addressing FGC/M in African countries. Also, it has argued that $\mathrm{FGC} / \mathrm{M}$ violates international norms espoused by international human rights instruments most of which The Gambia is a party. It has been contended that this practice is discriminatory and undermines the rights to sexual autonomy of women since it seeks to control women's sexuality. It examines the provisions of the Women's Amendment Act of 2015 of The Gambia which prohibits FGC/M in the country. It is argued that the Act misses a great opportunity to incorporate some of the important provisions of the African Women's Protocol.

It should be noted that a legal prohibition is not necessarily a guarantee that girls and women would be protected against FGC/M. The law would need to be effectively enforced and implemented. This requires political will from the state. One can draw lesson from Burkina Faso's experience, which is being recognized as one of the few countries where the government has been able to effectively implement laws on FGC/M. Other strategies such as awareness creation, capacity building of law enforcers, participation of children and young people, livelihood skills for ex-circumcizers, dialogue with religious and traditional leaders, engagement with men and boys should be enhanced to complement the legal reform. Time will therefore tell how far well the government mean in what can only be described yet as a legal and policy success against FGC/M. This is in line with the UN General 
Assembly Declaration 2012, which enjoins states to adopt a holistic approach to addressing FGC/M.

\section{Notes}

1 World Health Organisation (WHO) 'FGM fact sheet' (2016) http://www.who.int/ mediacentre/factsheets/fs241/en/ (accessed 25 July 2020).

2 UNICEF Female genital mutilation/cutting: A Statistical overview and exploration of the dynamics change (2013).

3 WHO (n 1).

4 As above

5 A Koski \& J Heymann 'Thirty-year trends in the prevalence and severity of female genital mutilation: A comparison of 22 countries' (2017) 2 BMJ Global Health 1-8.

6 Gambia Bureau of Statistics (GBOS) The Gambia 2013 population and housing census preliminary results (2014).

7 WHO (n 1).

8 Gambia Bureau of Statistics (n 6) 222.

9 UNICEF Multiple indicator cluster survey MICs (2018) 354-360.

10 A Kaplan et al 'Health consequences of female genital mutilation/cutting in the Gambia, evidence into action' (2011) 8 Reproductive Health 26.

11 UNICEF The Gambia: Statistical profile on female genital mutilation/cutting (2016).

12 S Nabaneh \& A Muula 'Female genital mutilation/cutting: A complex legal and ethical landscape' (2019) 145(2) International Journal of Gynecology \& Obstetrics 253-257.; see also E Durojaye \& P Sonne 'A holistic approach to addressing female genital cutting (FGC) in Africa:The relevance of the protocol to the African charter on the rights of women' (2011) Akungba Law Review 240-259.

13 For a detailed discussion on this see, F Banda Women, law and human rights: An African perspective (2005); see also R Murray 'A feminist perspective on reform of the African human rights system' (2001) 2 African Human Rights Law Journal 205-224.

14 Canadian Legal Network HIV Briefing paper on Criminal law and HIV (2008) 12.

15 S Nabaneh 'The impact of the African charter and the Maputo Protocol in The Gambia' inV Ayeni (ed) The impact of the African Charter and Maputo Protocol in selected African States (2016) 75-93.

16 Report of the Special Rapporteur on violence against women' Cultural practices in the family that are violent towards women' E/CN.4/2002/83 para. 6, 31 January 2002.

17 UN News Centre 'Ban welcomes UN General Assembly resolutions eliminating female genital mutilation' (2012) http://www.un.org/apps/news/story.asp?NewsID=43839 $\& \mathrm{Cr}=$ female + genital+mutilation\&Cr1\#.Vw3z2qQrLIU (accessed 12 July 2020).

18 UN Women 'Agreed conclusions on the elimination and prevention of all forms of violence against women and girls' (2013) http://www.un.org/womenwatch/daw/csw /csw57/CSW57_Agreed_Conclusions_(CSW_report_excerpt).pdf (accessed 15 July 2020).

19 T Hobbes Levithians (1651).

20 C Beccaria On crimes and punishments (1963) 14.

21 As above.

$22 \mathrm{~J}$ Betham (ed) An introduction to the principles of morals and legislation (1948) 125.

23 R Hood The death penalty: A worldwide perspective (1996) 238, see also. UN Human Rights Office of the High Commission Moving away from the death penalty: Arguemnts, trends and Perspective (2015).

24 Amnesty International 'Death sentences and executions 2010' (2011) 12.

25 UNICEF Female genital mutilation/cutting:A Statistical overview and exploration of the dynamics change (2013) 3 . 
26 H Rodney \& D Efua Child protection and female genital mutilation: Advice for health, education, and social work professionals (1992) 12.

27 R Cook et al 'Female genital cutting (mutilation/ circumcision): Ethical and legal dimensions' (2002) 79 International Journal of Gynecology and Obstructers 281-287.

28 I Gunning 'Arrogant perception, world traveling and multicultural feminism: The case of female genital surgeries' (1992) 23 Columbia Human Rights Law Review 189-248.

29 T Tyler Why people obey the law (1990) 18.

30 As above 19.

31 As above 23.

$32 \mathrm{R}$ Cook et al Reproductive health and human rights. Integrating medicine, ethics and law (2003).

33 National Women Bereau 'Female genital mutilation in The Gambia: A desk review' (2002) 23-24.

34 'Daily Observer 'President Jammeh bans FGM in Gambia' (25 November 2015).

35 UNFPA 'Implementation of international and regional human rights frameworks for the elimination of FGM' (2014).

36 Nabaneh \& Muula (n 12) 256.

37 Nabaneh \& Muula (n 12).

38 K Appiah The honor code: How moral revolutions happen (2010).

39 Tyler (n 29).

40 Human Rights Council 'Report of the Working Group on the Universal Periodic Review - Gambia'A/HRC/14/6 (2010).

41 J Materson \& J Swanson Female genital cutting: Breaking the silence, enabling change (2000) 10. 42 As above.

\section{References}

Amnesty International Death sentences and executions 2010 (Amnesty International 2011)

Appiah, K The honor code: How moral revolutions happen (W.W Norton 2010)

Banda, E Women, law and human rights: An African perspective (Oxford Hart Publishing 2005).

Barsoum, B, Rifaat, N, El-Gibaly, O, Elwan, N \& Forcier, N 'National efforts towards FGM-free villages in Egypt: The evidence of impact' Tech. Rep. 22 (Population Council 2011)

Beccaria, C On crimes and punishments (Macmillan 1963)

Bentham, $\mathrm{J}$ An introduction to the principles of morals and legislation (with an introduction by $\mathrm{W}$ Harrison) (Hather Publishing Company 1948)

Canadian Legal Network on HIV Briefing paper on criminal law and HIV (Canadian Legal Network on HIV 2008)

Chege, J, Askew, I \& Liku, J An assessment of the alternative rites approach for encouraging abandonment of female genital mutilation in Kenya (Population Council 2001)

Cook, R, Dickens, B \& Fathalla, M 'Female genital cutting (mutilation/ circumcision): Ethical and legal dimensions (2002) 79 International Journal of Gynecology and Obstructers 281.

Cook, R, Dickens, B \& Fathalla, M Reproductive health and human rights. Integrating medicine, ethics and law. (Clarendon Press 2003)

Gambia Bureau of Statistics (GBOS) The Gambia 2013 population and housing census preliminary results (Gambia Bureau of Statistics 2014)

Gunning, I 'Arrogant perception, world traveling and multicultural feminism: The case of female genital surgeries' (1992) 23 Columbia Human Rights Law Review 189

Hobbes, T Levithians (Oxford 1651)

Kaplan, A, Hechavarria, S, Martin, M \& Bonhoure, I 'Health consequences of female genital mutilation/cutting in the Gambia, evidence into action' (2011) 8 Reproductive Health 26 
Koski, A \& Heymann, J 'Thirty-year trends in the prevalence and severity of female genital mutilation: A comparison of 22 countries' (2017) 2 BMJ Global Health 1

Materson, J \& Swanson, J Female genital cutting: Breaking the silence, enabling change (International Centre for Research on Women \& the Centre for Development and Population Activities 2000)

Murray, R 'A feminist perspective on reform of the African human rights system' (2001) 2 African Human Rights Law Journal 205

Nabaneh, S 'The impact of the African Charter and the Maputo Protocol in The Gambia' in Ayeni, V (eds) The impact of the African Charter and Maputo Protocol in selected African states (Pretoria University Law Press 2016)

Nabaneh, S \& Muula, A 'Female genital mutilation/cutting: A complex legal and ethical landscape international' (2019) 145(2) Journal of Gynecology \& Obstetrics 253

Population Reference Bureau Abandoning female genital cutting: Prevalence, attitudes and efforts to end the practice (Population Reference Bureau 2001)

UNFPA Implementation of international and regional human rights frameworks for the elimination of FGM (UNFPA 2014)

UNFPA 'UNFPA-UNICEF joint programme on female genital mutilation/cutting: Accelerating change' Annual Report 2011 (UNFPA 2012)

UN Human Rights Office of the High Commission Moving away from the death penalty: Arguemnts, trends and perspective (OHCHR 2015)

UNICEF Female genital mutilation/cutting: A statistical overview and exploration of the dynamics change (UNICEF 2013)

World Health Organization 'FGM fact sheet' (2016) http://www.who.int/mediacentre/ factsheets/fs241/en/ (accessed 25 July 2020) 